\title{
Resenha
}

\section{EDUCAÇÃO POPULAR E DOCÊNCIA}

\author{
Marissandra Todero ${ }^{1}$ \\ Tatiane Fernanda Gomes ${ }^{2}$
}

O livro Educação Popular e Docência foi publicado em 2014 pela Editora Cortez, como parte da coleção "Docência em formação", integrando a série "Educação de Jovens e Adultos". A referida coleção reúne os resultados de reflexões, pesquisas e experiências de vários professores especialistas de todo o país, propondo uma integração entre a produção acadêmica e o trabalho nas escolas e dedica-se a subsidiar tanto a formação inicial quanto a formação continuada de profissionais da área educacional. A obra está organizada em sete capítulos, sendo o último deles escrito em forma de diálogo entre todos os autores.

No Capítulo 1, "Educação com o povo: notas históricas", é feita uma breve retomada histórica da educação popular, buscando contextualizar no cenário latino-americano, as lutas e movimentos de cultura que deram sentido de "povo" ao termo "popular". Também, neste texto, são relembrados momentos e pessoas que foram importantes para a construção daquilo que hoje se compreende por educação popular. A história da educação popular é marcada por dois aspectos: o primeiro as compreensões sobre o qualificativo popular na educação e o segundo, as possíveis caracterizações históricas da educação feita "com" e "para" o povo e em seu favor. A Educação popular com significados e sentidos próprios, da vida do povo, que encontram nas experiências libertadoras a vivência da práxis educativa como espaço de humanização e conscientização. No contexto brasileiro, marcado pelo descaso com a educação dos populares, aparece como referência o grande educador Paulo Freire, na década de 1960, na mesma direção há outros educadores com compromisso ético-político com as classes populares, com metodologias próprias e libertadoras, pessoas que combinam a educação com projeto de sociedade.

Com o golpe Militar de 1964, o Brasil passou a viver sob suas normas e

1 Aluna do Mestrado Profissional em Educação da Universidade Federal da Fronteira Sul (UFFS). Professora da rede municipal de Quatro Irmãos - RS. E-mail: marissandrat@gmail.com.

2 Aluna do Mestrado Profissional em Educação da UFFS. Servidora técnico-administrativa da Universidade Federal de Santa Maria (UFSM). E-mail: tatiane@ufsm.br. 
regras. Neste sentido, a educação popular era considerada como uma ferramenta política, segundo Haddad e Di Pierro, 2000. Neste período que se atribuiu à educação de adultos seu compromisso de resgate e valorizar os saberes populares, fazendo dessa o motor de um movimento mais amplo de valorização da cultura popular. Nos anos 1980, período de redemocratização, a redação da nova constituinte não garantiu o fim dos privilégios do setor privado da educação, ainda que o Estado tenha assumido a obrigatoriedade e a garantia do ensino, a política educacional estava fortemente identificada com o autoritarismo dos militares. No final desta década, inspirados em Paulo Freire, surgiram diversos movimentos dentre eles, o Movimento de Alfabetização de Jovens e Adultos - MOVA, que buscava a participação e a luta pelos direitos do cidadão, voltada a uma leitura crítica da realidade, para sua transformação e luta pela justiça.

Na sequência do livro, é trazida uma reflexão sobre "Aproximações teóricas em educação popular". São apresentadas algumas características da pedagogia da educação popular e a identificação de algumas aproximações teóricas que entram em sua construção. Nesta aproximação, são destacados alguns dos precursores que influenciaram o pensamento e a obra de Paulo Freire, um dos principais expoentes latino-americanos da educação popular. Não ignorando as bases do pensamento moderno (autores como Descartes, Locke, Rousseau, Kant e Hegel, entre outros exemplos), apresenta articulações compreendidas como fundamentos teóricos da educação popular, como o marxismo, o existencialismo, a fenomenologia, a Escola de Frankfurt, a Escola Nova, a Teoria da Reprodução e autores latino-americanos como Martí, Dussel e Freire. Os nomes aqui citados e outros tantos que fazem parte do texto, de autores e de teorias mencionados, objetivam servir como um convite para leitura e aprofundamentos. Neste movimento político e pedagógico em que a educação popular se constrói, tem sua base nos diferentes contextos vividos pelos sujeitos, seus ideais, suas subjetividades, seus limites e a busca da transformação através da valorização da cultura do povo.

No terceiro capítulo, questiona-se sobre “Quem é o educador popular?”. O educador ou a educadora popular, entendida como uma entidade fixa, quem sabe nem exista, mas como ser comprometido e chave do processo que se revelam nos contextos, com necessidade de mudança que se coloca em luta pela participação, pela igualdade, pela justiça social, pelo respeito, pela cidadania, pela valorização e reconhecimento do diferente. O educador popular, pelas suas experiências e vivências de busca de emancipação nas relações estabelecidas, 
como chave do processo educativo, pode ser encontrado em diferentes espaços, como: nos movimentos populares, nas escolas e universidades, na execução das políticas sociais, na Educação de Jovens e Adultos, nas Organizações não governamentais - ONGs, entre outros espaços que buscam na educação popular ancoras para a emancipação dos sujeitos, preparando-os para a vida, através da leitura crítica de sua trajetória e do mundo que os rodeia.

"Educação Popular e Políticas públicas: Entre o Instituído e o instituinte" é o quarto capítulo e explora as múltiplas dimensões que envolvem a relação entre Educação Popular e Estado. Para ilustrar essa relação, são apresentadas experiências em torno da luta de educadores populares por formação e conquistas sociais, a atuação das organizações não governamentais - ONGs e sua influência em relação às políticas públicas e as tensões na implementação de políticas de proteção social no âmbito municipal, com base na educação popular, abordando também a democratização do processo de decisões sobre o orçamento público como possibilidade de ampliação da democracia e a constituição de espaços pedagógicos permanentes e os dilemas em torno do marco de referência da educação popular para as políticas públicas. Com relação às políticas de assistência social e ONGs, é mencionada a possibilidade de efetivação de ações descentralizadas através da ação das ONGs, entretanto, adverte-se que algumas políticas sociais implementadas nesse modelo têm efetividade apenas em caráter compensatório, ou seja, são ações de implementação imediata, mas sem consequências sólidas a médio e longo prazo. As tensões na implementação de políticas públicas na assistência social são ilustradas a partir de implicações na implantação dessa política no município de Novo Hamburgo - RS. A seguir, o orçamento participativo é apresentado como um espaço com importante potencial pedagógico de formação da cidadania, o que encaminha para o elemento seguinte: "Diálogo entre os saberes instituídos e instituintes" no qual são descritas ações promovidas por educadores da Associação de Educadores Populares de Porto Alegre - AEPPA, em busca do direito à formação permanente de educadores populares. A mobilização da AEPPA conquistou o Curso de Pedagogia na UFRGS, e as educadoras da associação participaram do processo de escrita do Curso de Pedagogia de Educação Popular, posteriormente, a parceria com instituições privadas houve a realização do curso de Pedagogia com ênfase em educação popular na Pontifícia Universidade Católica do Rio Grande do Sul PUC-RS, além da construção de um curso de especialização em Educação Popular e Movimentos Sociais, realizado no Instituto Brava Gente. Essas 
oportunidades formativas foram importantes, mas não resultaram em políticas públicas. Dos cursos mencionados, o único que permanece é a especialização em educação popular. Na sequência, são comentados os dilemas que decorrem da implantação do marco de referência em educação popular para as políticas públicas, documento elaborado pelo governo federal. Destaca-se que se trata de uma proposição que surge externamente, fora do contexto político e social brasileiro e esse fator gera desconfiança, entretanto, apresenta aspectos positivos em relação à agenda popular. Uma questão bastante preocupante é incerteza de que a participação oficializada prejudique a autonomia das ações. Os autores defendem a construção da participação popular a partir de um projeto político e, apesar das contradições representadas pelo choque de interesses e perspectivas entre o que se sugestiona (externamente) e o que se espera (militância), se colocam esperançosos da possibilidade de avançar no que caracteriza basicamente a educação popular: a resistência e a criatividade.

O capítulo V "Pesquisa-Educação: prática docente e investigativa", parte da afirmação de que todo educador é um pesquisador e se organiza em torno de dois eixos, o primeiro apresenta perspectivas teórico-metodológicas voltadas à pesquisa-ação, pesquisa participante, pesquisa-ação participante e sistematização de experiências, trazendo autores como Thiollent, Santoro, Fals Borda, Brandão, Jara, Torres Carrillo. O segundo eixo, dedica-se à apresentação de princípios ou convergências metodológicas identificadas em comum nas práticas mencionadas no primeiro eixo, enfocando o diálogo com a prática educativa.

O sexto capítulo dedica-se à formação do educador popular e se estrutura em torno de vários questionamentos: como se forma o educador popular? Quem forma e onde se forma o educador popular? Qual o papel das diferentes agências formadoras? A compreensão de que o lócus da formação ultrapassa as fronteiras de um espaço específico é importante no reconhecimento da pluralidade de agências de formação e de sujeitos formadores, para os autores, "a formação é permanente, e o educador e a educadora, acima de tudo, forma-se desde o seu lugar de atuação, de militância” (p. 159). A partir do diálogo com um grupo de educadores e educadoras, constata-se que a participação em processos formativos informais é associada à formação acadêmica na construção por parte desses educadores de um perfil de educador e educadora popular. A formação dos educadores e educadoras populares se dá em um processo permanente e é alimentada pelo movimento de sua práxis.

O sétimo e último capítulo do livro, redigido em forma de diálogo entre os 
autores, compõe um exercício coletivo que toma como objeto de reflexão a relação entre a educação popular e a Educação de Jovens e Adultos - EJA. Relata a proximidade entre a educação popular e a EJA e reflete em torno das políticas recentes que incorporaram a EJA como uma das modalidades integradas no sistema oficial de ensino que busca constituir-se como um espaço pedagógico com características próprias. Também são mencionadas algumas vivências pessoais da caminhada dos autores, relacionadas à pesquisa em educação popular, a relação teoria-prática, e é enfatizada a importância do educador, mesmo na educação formal, respeitar um paradigma pedagógico crítico e utópico com relação à sociedade. Dessa forma, é possível fazer educação popular em um ambiente formal, no caso a EJA, através da adoção de práticas metodológicas que auxiliem na superação dos limites e condicionantes desse espaço.

Educação Popular e Docência, como o próprio título indica, relaciona os temas educação popular e docência, apresentando tanto elementos históricos e teóricos quanto experiências reais, se constituindo uma obra interessante e rica. Considerando que faz parte de uma coleção voltada à formação inicial e continuada de profissionais da educação, representa uma grande contribuição a todos e todas que pensam, refletem e trabalham com a educação popular nos diferentes espaços em que ela acontece, sendo relevante também para quem tem seu primeiro contato com a temática. Há um equilíbrio entre os aspectos teóricos e históricos associados às reflexões educacionais levantadas com relação à formação de professores, tais reflexões culminam com o capítulo final, elaborado em forma de diálogo e que dá voz a cada um dos autores, destacando suas perspectivas e vivências e, também, a partilha destes saberes entre os pares, valorizando os conhecimentos individuais $\mathrm{e}$ as diferentes experiências vivenciadas nos contextos em que atuam.

\section{REFERÊNCIA}

STRECK, Danilo Romeu; PITANO, Sandro de Castro; MORETTI, Cheron Zanini; SANTOS, Karine dos; LEMOS, Marilene; PAULO, Fernanda dos Santos. Educação Popular e Docência. 1. ed. São Paulo: Cortez Editora, 2014. v. 1. 216 p. 
Resenha: Educação popular e docência 